\title{
EL COMPLEJO CULTURAL PARQUE DE ESPAÑA (ROSARIO, 1977-1992)
}

\author{
The Complejo Cultural Parque de España (Rosario, 1977-1992)
}

Guillermo S. Robles*

\section{Resumen}

En este artículo se analiza al Complejo Cultural Parque de España (CCPE) como ícono arquitectónico de la ciudad de Rosario, fruto de iniciativas personales e institucionales de la comunidad española radicada en esa ciudad. La prensa periódica, los diversos informes y proyectos elaborados por los organismos que componen al CCPE y las memorias escritas por algunos de los protagonistas, dan cuenta de una relación dinámica -y no exenta de algunos conflictos- entre la colectividad ibérica rosarina y diversas agencias estatales locales y españolas, atravesando disímiles contextos histórico-políticos, desde mediados de la década de 1970 hasta momentos recientes.

$<$ Rosario $><$ Complejo Cultural Parque de España $><$ colectividad española $>$

\begin{abstract}
This paper analyzes the Complejo Cultural Parque de España (CCPE) as an architectonic icon of the city of Rosario, which is the result of personal and institutional initiatives of the Spanish community established in this city. Since the mid-Seventies up to date, the periodical press, across dissimilar historicalpolitical contexts, the different reports and projects prepared by the CCPE's organisms and the memories written by some of its protagonists, show a dynamic -although not exempt from conflicts- relationship between Rosario's Iberian community and the different local and Spanish state departments.
\end{abstract}

$<$ Rosario $><$ Complejo Cultural Parque de España $><$ Spanish community $>$

Recibido: 21/07/2014 // Aceptado: 10/10/2014

* Licenciado en Historia, Centro Regional Rosario - Universidad Nacional de Concepción del Uruguay,

sebastianbles@hotmail.com 


\section{Introducción: La colectividad española en Rosario}

La inauguración en 1992, en el marco de la conmemoración del V Centenario del Descubrimiento de América, del Complejo Cultural Parque de España en las barrancas del río Paraná, bien puede leerse como el punto culminante del desarrollo de la colectividad española en Rosario.

Como señala Hilda Habichayn, la presencia de españoles en la ciudad se remonta desde los inicios de la misma, verificable a fines del siglo XVIII en el asentamiento denominado Pago de los Arroyos (Habichayn, 1991). Así, el considerado primer cronista de Rosario, Pedro Tuella y Mompesar, era oriundo de la Villa de la Naval, en Huesca $^{1}$. Apellidos ibéricos como los de Gómez Recio, Romero de Pineda, Montenegro, Echeverría, Basualdo, Villarruel, Urraco, Gayoso y Espinosa, aparecen en las primeras crónicas de esta ciudad sin fundador conocido. Y el censo realizado por Tuella, publicado en 1802 en el "Telégrafo Mercantil, Rural, Político, Historiográfico del Río de la Plata" da cuenta de que de los 5879 habitantes del Pago, 4934 eran españoles.

Esta presencia española "originaria" iba a aumentar considerablemente durante las últimas décadas del siglo XIX y las primeras del XX, debido a las migraciones transatlánticas. Si bien en cuanto a las nacionalidades de origen de las mismas, a nivel provincial, la tendencia mayoritaria estuvo representada por los italianos, los españoles fueron los más proclives a radicarse en los asentamientos urbanos como Santa Fe y Rosario (Sonzogni, 2006: 20).

Es entonces durante dicho período donde podríamos ubicar la conformación de una colectividad española en Rosario, a partir del nacimiento de instituciones que reivindican su representación en la ciudad. En primer lugar, la Asociación Española de Socorros Mutuos de la ciudad de Rosario, fundada el $1^{\circ}$ de julio de 1857 , que se atribuyó para sí el carácter de asociación mutualista pionera en el ámbito del territorio nacional argentino (Fernández y Galassi, 2006: 48-49)². Y luego, debemos consignar aquellas instituciones que agruparon a los españoles según su origen regional (entre paréntesis la fecha de fundación): Centre Catalá (2 de marzo de 1902); Centro Vasco Zazpirak Bat (21 de julio de 1911); Centro Gallego (5 de noviembre de 1956); Centro Navarro (6 de diciembre de 1913); Centro Asturiano (1 de noviembre de 1904); Centro Castilla (20 de agosto de 1920) y Centro Andaluz (30 de septiembre de 1915). (Habichayn, 1991: 15-21). La mayoría de estas agrupaciones constituyeron en 1969 la Federación de Asociaciones Españolas de la Provincia de Santa Fe, que se constituyó como entidad destinada a promover el intercambio artístico, turístico, intelectual, cultural y económico

\footnotetext{
El mismo cronista visibiliza la presencia de españoles en las primeras actividades comerciales y en oficios que se desarrollaban en el Pago: la primera panadería fue del español Gumersindo Trigo; el primer albañil conocido, el vizcaíno Mateo Fernández; los primeros servicios de mensajerías con diligencias fueron establecidos por los catalanes Juan Rusiñol y Joaquín Fillol. En Habichayn, Hilda. 1991. "La colectividad española". En: AA.VV. Rosario. Historias de aqui a la vuelta. Tomo II. Rosario, Ediciones de Aquí a la Vuelta, pp. 2-3.

2 Existen una serie de trabajos de investigación sobre la Asociación Española de Socorros Mutuos de Rosario, desarrollados por historiadores, antropólogos y agrimensores de la Universidad Nacional de Rosario compilados en De Grandis, Nélida. 2007. Los españoles en sociedad: inmigración, territorio y trama asociativa en Rosario. Rosario, el autor.
} 
entre España y Argentina y para coordinar las actividades de todas las instituciones que la integran, respetando la autonomía de cada una de ellas ${ }^{3}$.

No debemos olvidar en esta enumeración al Club Español, fundado el 8 de octubre de 1882, que con el tiempo se proyectó como un espacio de sociabilidad distinguido, para profesionales y comerciantes españoles en ascenso, que se relacionaron con los sectores encumbrados de la sociedad rosarina (Águila, Galassi y García, 2004: 17).

Las décadas de 1920 y de 1930 pueden ser consideradas como las más esplendorosas para la comunidad española en Rosario. La colectividad participa en la creación de su propia memoria colectiva a partir de la producción de libros y folletos; la organización de conferencias y de celebraciones (como las de conmemoración del 12 de octubre) (Videla, 2004: 13).

Las siguientes palabras del historiador rosarino Oscar Videla nos proporcionan una buena imagen del impacto de la comunidad española en Rosario:

"Puesta la mirada poco más de ochenta años atrás, la presencia española en Rosario era tan evidente que las más variadas facetas de la vida cotidiana lo resaltaban a cada paso. Casi dos de cada diez rosarinos que caminaban por sus calles habían nacido en España, algunos de los más lujosos edificios de la ciudad denotaban claramente la mano de los arquitectos peninsulares, muchos de los más importantes hombres de negocios y aún de los políticos locales también eran de ese origen, y por supuesto también lo eran muchos de esos esforzados militantes sociales responsables de que a la pujante urbe no solo se la comparara con la también cerealera Chicago, sino con la socialmente encendida Barcelona. Todos los tipos sociales de una ciudad moderna que ya era Rosario estaban representados entre los españoles, desde el típico 'gallego' almacenero, pasando por las explotadas trabajadoras cigarreras hasta el último hombre de negocios. Nuestro presente no es tan rico en esos variopintos prototipos, pero la impronta de los españoles continúa claramente visible en múltiples aspectos de la vida de la ciudad. Y es que luego de una presencia que lleva siglos, ésta ha sido parte tan consustancial de Rosario que forma parte indudable de su propia identidad"4

\footnotetext{
3 Hay que aclarar que en España, la creación de las comunidades autónomas y las elecciones municipales de los años 1979/1980, dieron juego a las relaciones externas y de cooperación con las instituciones regionales y locales. Estas encontraron rápidamente pares e interlocutores en América Latina en la figura de ayuntamientos, clubes y organismos de emigrantes españoles afincados en esos países, frecuentemente organizados según lugares de origen y preocupados por mantener sus identidades, lengua, pautas culturales, hábitos gastronómicos, etc. Durante toda la década de los ochenta tales relaciones se incentivaron con énfasis (Iturrieta, 1993: 187). Así, se fundan en Rosario nuevos centros regionales como el Centro Aragonés, Centro Extremeño, Centro Balear, Centro Valenciano, Rincón Murciano y Centro Riojano Español.

${ }^{4}$ Videla, Oscar. "Los españoles en Rosario”. En: Sandra Fernández y María Rosa Oliver (coord.), 2004.
} 


\section{El proyecto Parque de España (1977-1980)}

Con motivo del vigésimo aniversario de la inauguración del Complejo Cultural Parque de España (de ahora en adelante CCPE) se publicó en Rosario una lujosa edición coordinada por los arquitectos Roberto De Gregorio, Viviana Mesanich y Ana María Sánchez ${ }^{5}$. En la misma, además de la profusión de fotografías que ilustran los diferentes momentos de la construcción y los diferentes espacios que conforman el Complejo, se recogen los testimonios de los actores que participaron de la proyección y concreción de dicha obra. Dichos testimonios más los artículos y noticias aparecidos en la prensa diaria y periódica de la ciudad de Rosario, son los que nos permiten reconstruir las diferentes etapas y acontecimientos que se sucedieron alrededor de la construcción de uno de los íconos urbanísticos más importantes de la ciudad de Rosario.

Los diferentes testimonios coinciden en indicar los últimos años de la década de 1970 como el momento en que se gestó la idea, por parte de la colectividad española de Rosario, de dotar a la ciudad, como forma de agradecimiento por su acogida, de un parque de importantes dimensiones que llevara el nombre de España. El Consulado General de España en Rosario, a través de su entonces Canciller Gerardo Hernández Illanes y la Federación de Asociaciones Españolas de la Provincia de Santa Fe, fueron las instituciones que impulsaron originalmente el proyecto.

El antecedente más inmediato del mismo lo constituyó la inauguración, en 1977, del Colegio Español. El historiador rosarino Miguel Ángel De Marco (que como veremos más adelante fue también protagonista en el desarrollo del proyecto) recuerda que:

“...el establecimiento se hallaba en dependencias anexas a la Parroquia Nuestra Señora del Pilar, que pronto resultarían insuficientes. Gerardo [Hernández Illanes] deseaba obtener un lugar definitivo para el Colegio y pensó que el antiguo anhelo de la colectividad de que se diese el nombre de España a uno de los parques principales de Rosario, podría contribuir a su propósito. Pensó que se podría construir dentro del predio ya no sólo el colegio sino un Complejo Cultural y Educativo mucho más amplio"'.

Ese mismo año comenzaron las conversaciones con las autoridades municipales. En agosto, el intendente, capitán de navío Augusto Félix Cristiani, a quien secundaba

Catálogo fotográfico del Club Español de Rosario. 1882-1940. Rosario, Club Español de Rosario y Prohistoria, pp. 11.

${ }^{5}$ Quiero agradecer aquí al Señor Apoderado-Administrador de la Fundación Centro Cultural Parque de España, Dr. Gerardo Hernández Illanes, quien generosamente me ha obsequiado un ejemplar de dicha edición. Asimismo debo agradecer también a su secretaria, Diana Sánchez Mateos, quien le ha comunicado mi intención de escribir este artículo, facilitando de esa manera la posibilidad de entrevistarme con él.

6 De Marco, Miguel Ángel. 2012. "La fuerza de un sueño". En: Roberto De Gregorio, Viviana Mesanich y Ana María Sánchez (coord.) Complejo Cultural Parque de España, s/e, pp. 14. 
en el área respectiva el ingeniero Juan Carlos Gurmendi, anunció al cónsul español, Fernando Valenzuela Marzo, que la Municipalidad estaba dispuesta a ceder los espacios necesarios. Cuando se efectuó la elección de los terrenos, Gerardo Hernández propuso a las autoridades aprovechar el amplio predio asignado en la franja central ribereña, para establecer un complejo cultural en el que además de levantarse el local propio del Colegio Español, se erigiesen un Centro Cultural, la Biblioteca Hispánica, el Centro de Estudios Iberoamericanos, el Instituto de Cultura Hispánica y otras dependencias. Para realizar un estudio de las posibilidades que ofrecía el terreno cedido por la Municipalidad se invitó a los arquitectos españoles Oriol Bohigas y Josep Martorell7 . La visita del primero, a principios de 1978, dio origen al llamado a concurso del proyecto ejecutivo y la realización de diversos trabajos, en los que participaron profesores y alumnos de la Facultad de Arquitectura de la UNR. Con la colaboración del arquitecto David Mackay, se confeccionaron diversos planos y estudios de los viejos muelles asentados en la costa. En una segunda recorrida, en abril-mayo de 1979, el arquitecto Bohigas sugirió integrar al Complejo cinco túneles del siglo XIX, que eran utilizados para los trabajos de carga y descarga del viejo puerto, ubicado en el predio donde se levantaría la obra. (De Marco, 2012: 17).

Se hace presente entonces en esta etapa del proyecto otro actor institucional central en esta obra: el Centro de Arquitectos de Rosario (de ahora en adelante CAR). A partir de 1955 se inicia un período en la Escuela de Arquitectura de Rosario (dependiente por entonces de la Universidad Nacional del Litoral) caracterizado por una renovación profunda de su claustro de profesores. Francisco Bullrich, Jorge Enrique Hardoy, Carlos Méndez Mosquera, Iván Hernández Larguía y Juan Manuel Borthagaray, por citar algunos, impulsaron en las aulas temas acordes con la realidad local y desarrollaron proyectos sobre terrenos existentes y disponibles, evitando aquellos inalcanzables y de carácter idealista. En los debates realizados en los llamados "talleres verticales", se formaron un considerable número de arquitectos, quienes años después, asumieron roles protagónicos en el momento en que se materializaba la obra del CCPE (De Gregorio, 2012: 102).

Fue en un Encuentro de Arquitectos en Santiago de Chile, en el año 1972, donde un grupo de profesionales pertenecientes al CAR -Luis Reggiardo, Julio Mendoza, José Luis Jereb y Roberto Shiira, entre otros- toma contacto con Oriol Bohigas, en ese entonces no demasiado reconocido internacionalmente, a quien invitaron a Rosario a dar unas conferencias. El arquitecto catalán aceptó el convite y quedó fascinado con la magnitud del río Paraná (Schmidt, 2012: 88). Graciela Schmidt, que se desempeñaba

7 El estudio de los arquitectos Martorell y Bohigas, al que luego se le agregaría Mackay (de ahora en adelante MBM) inició sus actividades en la ciudad de Barcelona en la década de 1950, con una formación basada en la tradición del novecentismo y el modernismo catalanes. Bohigas fue su integrante con mayor resonancia mediática debido a su activa participación en debates y seminarios internacionales, así como su fomento a la creación de las Comisiones de Cultura en el Colegio de Arquitectos de Barcelona. (De Gregorio, Roberto. 2012. "Aportes tentativos para enfocar algunas interpretaciones". En: De Gregorio, Roberto; Mesanich, Susana y Sánchez, Ana María. Complejo Cultural Parque de España, s/e, pp.114$115)$. 
como Secretaria del CAR en 1978, recuerda la manera en que los arquitectos españoles se incorporan al Proyecto del CCPE, así como el primer esbozo del mismo:

\begin{abstract}
“...Tiempo después el Consulado de España y las asociaciones españolas de nuestra ciudad presentaron al CAR, una idea sobre la parquización de un área ferroviaria sobre la costa, que la Municipalidad gestionaba para comunidad. Pensaban, inicialmente, hacer un paseo donde se ubicarían, sobre bases con los correspondientes escudos de las provincias españolas, los bustos de destacadas personalidades representantes de las artes, ciencias y literatura que prestigiaron a través de los tiempos la cultura ibérica. Para diseñar la obra propusieron una terna, de la que se optó por el estudio catalán de los arquitectos Bohigas-Mackay-Martorell. Nuestro Centro debía organizar, a posteriori del anteproyecto realizado por los españoles, un concurso de antecedentes entre sus matriculados para seleccionar a los profesionales locales que se harían cargo del proyecto ejecutivo"8.
\end{abstract}

El arquitecto Fernando Boix formó parte, junto con su colega Guillermo Viarengo y el estudiante Ricardo Gurmendi, del grupo que acompañó a Oriol Bohigas en 1978 en los trabajos preliminares necesarios para el diseño e inicio de las obras (el armado planimétrico del sitio, relevamientos fotográficos, etc.). Recuerda de la siguiente manera la relación mantenida entonces con el arquitecto catalán, dando cuenta de las fuertes convicciones de éste a la hora de entablar negociaciones con miembros de la élite rosarina:
“...Formábamos un grupo podríamos decir de 'colaboradores' de Bohigas, que trabajábamos junto con representantes de la Municipalidad de Rosario y miembros del Consulado...Como hecho curioso puedo destacar el absoluto secreto en que nos movíamos, tratando de que no se hiciera público en los inicios este proyecto que estaba recién en germen.
Nos hacían acompañarlo a encuentros con empresarios del ám- bito local, quienes están interesados en conocer y ver cómo se

\footnotetext{
8 Schmidt, Graciela. 2012 "Participación del Centro de Arquitectos". En: Roberto De Gregorio, Viviana Mesanich y Ana María Sánchez (coord.) Complejo Cultural Parque de España, s/e, pp. 88. Existe una interesante nota periodística en la prensa local donde se desarrollan sendas entrevistas al Cónsul General de España en Rosario, Fernando Valenzuela Marzo; al subsecretario de Planeamiento de la Municipalidad de Rosario, Juan Carlos Gurmendi y al presidente del CAR, Rufino de la Torre. Ver: Sin Autor. 1978. "Recuperando el río para Rosario. Esto será convertido en el parque España". En: El País en la Noticia, Rosario, domingo 19 de febrero de 1978, pp. 8-9.
} 
podía invertir en este proyecto. Nosotros íbamos como apoyatura técnica.

Particularmente recuerdo una reunión que se realizó en el salón Mercurio de la Bolsa de Comercio, allí se suscitaron algunas discusiones, donde los inversionistas pedían reglamentaciones para poder intervenir en este emprendimiento. Y me quedaron grabadas muy claramente las palabras de Bohigas, quien les dijo a los empresarios rosarinos que 'un buen proyecto de arquitectura no se reglamenta, sino se hace con la firma de un buen arquitecto'. El estaba verdaderamente preocupado por resolver un proyecto que contemplara las múltiples cualidades del sitio y de la arquitectura a la que tenía que dar respuesta".

En julio de 1980, Bohigas y Martorell presentaron en la Municipalidad de Rosario y en el Museo Municipal de Bellas Artes “Juan B. Castagnino" el denominado "proyecto básico" del Parque de España. En la presentación municipal estuvieron acompañados de los Secretarios de Gobierno, Mario Alberto Casanova; de Planeamiento, Juan Carlos Gurmendi; de Obras Públicas, Vicente José Laraja; de Hacienda, Ronald Esmendi; de Servicios Públicos, Héctor Prat, y de Salud Pública, Roberto Sánchez Ordóñez. En la conferencia de prensa también estuvieron presentes el cónsul general de España en Rosario, Fernando Valenzuela Marzo; el canciller del Consulado General de España, Gerardo Hernández Illanes, y representantes de la Federación de Entidades Españolas de la Provincia de Santa Fe ${ }^{10}$. El diseño presentado en esa ocasión, concebía al CCPE como un sector público parquizado de transición entre la ciudad y el río. El Parque se extendería a lo largo de 12 hectáreas sobre la franja costera central y se organizaba transversalmente según tres fajas longitudinales (Schmidt, 2012: 88) de la siguiente manera:

“...el sector este para actividades culturales y de significaciones conmemorativas; el central, destinado a ferias y exposiciones temporales; el oeste, para las funciones de ocio y diversión. El primero estaba constituido por el edificio del Centro de Cultura Hispánica a nivel del muelle, con una cubierta que se integraba al parque como una entrada formalizada al paseo de las palmeras; el sendero-itinerario con la serie de pequeños monumentos de grandes figuras de la cultura española; el puente mirador, estructura metálica elevada para atravesar peatonalmente desde la plaza Guernica hasta asomarse al río.

\footnotetext{
9 Brarda, A. 2012. "Entrevista al Arquitecto Fernando Boix". En: Roberto De Gregorio, Viviana Mesanich y Ana María Sánchez (coord.) Complejo Cultural Parque de España, s/e, pp. 92.

${ }^{10}$ Sin Autor. 1980. "Fue presentado el anteproyecto del parque España de Rosario". En: La Capital, Rosario, jueves 17 de julio de 1980, pp. 9).
} 
El simbolismo de los elementos del diseño fue especialmente considerado por los proyectistas. Ese puente se constituyó como el signo de mayor representatividad del parque. Siguiendo la octogonalidad de las calles, remitía a la herencia urbana española. La cascada de agua, prevista en su extremo con la caída hacia el Paraná, reflejaba el constante fluir espiritual entre las dos culturas, americana y española. El jardín y el paseo de las palmeras representaban las huellas de la estructura original geográfica y humana del ámbito americano.

En el sector central se utilizaban todos los viejos edificios del ferrocarril con la Estación Rosario Central como centro de ferias y exposiciones. Los demás edificios se destinaban a servicios anexos y a un museo ferroviario.

El sector oeste se desarrollaba alrededor de un lago y un montículo, artificiales, recreando un paisaje natural que acompañaba ese especial micro-ambiente que conservaban aún las instalaciones de recreo de los clubes de pescadores. Reutilizando el existente galpón 'Peñaflor', se preveía un gran restaurante-asador de carácter popular. La parquización de ambos sectores manifestaba las dos morfologías paisajistas más extremas de las variadas regiones de España”"

Meses después, juntamente con miembros del CAR, Bohigas y Martorell se constituyeron en jurados del Concurso para seleccionar a los profesionales que se harían cargo del proyecto ejecutivo. Fueron elegidos el Estudio Quiroga y Asociados, para el proyecto de Arquitectura y el Estudio H, para el de Paisaje y Vialidad. (De Marco, 2012: 17).

\section{La ejecución de la obra (1980-1992)}

Doce años transcurrieron entre la adjudicación del proyecto ejecutivo y la inauguración de la obra. Con el objetivo de conformar una entidad con capacidad jurídica para gestionar los fondos que permitieran su concreción, se conformó en 1980 el Comité Ejecutivo del Parque de España, presidido por Gerardo Hernández Illanes e integrado por Sandalio Monreal, Gregorio Lizarbe, Jesús Azanza, José María Fontela, Vicente Suárez, Mariano Lorente, Antonio García y Carlos Giandoménico, incorporándose como asesor técnico el arquitecto Horacio Quiroga. El presidente del mismo recuerda que entre 1980 y 1984 "deambulamos por distintos centros de poder tanto argentinos como españoles, sin poder lograr respuestas firmes que nos hiciesen alentar expectativas de concretar nuestro sueño"12. Si pensamos en las coyunturas políticas por las que atravesaban ambos

\footnotetext{
${ }^{11}$ Schmidt, Graciela. 2012. "Participación del Centro de Arquitectos". En: Roberto De Gregorio, Viviana Mesanich y Ana María Sánchez (coord.) Complejo Cultural Parque de España, s/e, pp. 88.

12 De Marco, Miguel Ángel. 2012; op.cit., pp. 17.
} 
países en aquellos años, signadas por la dictadura militar y su posterior derrumbe debido a la Guerra de Malvinas en la Argentina, así como los múltiples desafíos creados por la transición a la democracia luego de la muerte de Francisco Franco en España, nos atrevemos a afirmar que no se trataba del mejor momento para hacer interesar a las autoridades estatales en una agenda de desarrollo del patrimonio cultural. El testimonio brindado por Horacio Quiroga, el arquitecto encargado del proyecto ejecutivo y también integrante del Comité Ejecutivo, en la publicación editada con motivo del vigésimo aniversario de la inauguración del CCPE, ilustra de manera detallada (y con una carga nada desdeñable de ironía) los acontecimientos que se sucedieron durante estos doce años.

Según el testimonio de Quiroga, los inconvenientes financieros se presentaron en el mismo momento en que se adjudicó a su estudio de arquitectura la ejecución de la obra, inconvenientes momentáneamente compensados gracias a la intervención de la colectividad española rosarina:

“...Producido el fallo...se sucedió un prolongado silencio... Lo que realmente estaba sucediendo es que el intendente Cristiani se enteró por boca de Bohigas que ahora había que pagar unos proyectos ejecutivos ya que los entregados por MBM eran insuficientes para construir las obras. De esta manera, nos encontrábamos ante una situación irrisoria donde por una parte habían mandado a proyectar un Parque en terrenos ajenos y por la otra, no se encontraba Comitente, es decir alguien que encargara y pagara los proyectos ejecutivos... Finalmente firmamos unos contratos entre los Estudios y la Federación de Asociaciones Españolas de la Provincia de Santa Fe. Esta elección fue en verdad un generoso gesto de la colectividad ya que el Consulado no podía firmar porque involucraba al Estado Español, y la Municipalidad no se sentía en absoluto obligada"13.

Para comprender mejor la coyuntura histórica local en la que se desarrollaron los diferentes momentos de la ejecución de la obra, atenderemos al trabajo de investigación realizado por la arquitecta Alicia Mateos sobre las políticas urbanísticas rosarinas entre 1976 y 1992 (Mateos, 2003). En el mismo se sostiene la hipótesis general que durante esos años "se produjo...un proceso de cambio que implicó el pasaje desde un modelo basado en la planificación tradicional genérica y abstracta pero a la vez rígida y reglamentarista, con fuerte presencia de la inversión pública hacia un modelo más flexible, basado en la gestión de programas y proyectos parciales y especificos, que apostó fuertemente a la atracción de capitales privados”14.

\footnotetext{
${ }^{13}$ Quiroga, Horacio. 2012. "Guión para hilvanar recuerdos del proyectista ejecutivo”. En: Roberto De Gregorio, Viviana Mesanich y Ana María Sánchez (coord.) Complejo Cultural Parque de España, s/e, pp. 88.

${ }^{14}$ Mateos, Alicia. 2003. "Las políticas urbanísticas para la ciudad de Rosario entre 1976 y 1992”. En: I
} 
La intendencia del Capitán Augusto Cristiani se inició en abril de 1976, luego de una corta intervención del Coronel Laciar, y concluyó en abril de 1981. Tuvo como Secretario de Planeamiento al Ingeniero Juan Gurmendi y como Secretario de Obras Públicas primero al Ingeniero Angelone (hasta agosto de 1977) y luego al Ingeniero Vicente Laraia. En este período se creó la Subsecretaría de Planeamiento a la que rápidamente se elevó su rango a Secretaría, integrada por las siguientes oficinas: Dirección de Planeamiento; Dirección de Planeamiento Urbano; Comisión Coordinadora Ferrourbanística y Dirección de Tierras y Tasaciones. La Secretaría se planteó así como una "súper oficina" para coordinar y planificar toda la gestión municipal. Fue durante esta gestión cuando se realizó el relevamiento y la delimitación del área para el futuro Parque España, estableciéndose que los costos del proyecto y la ejecución de la obra estarían a cargo de la colectividad española; habían también comenzado las tratativas con el gobierno español y el arquitecto Oriol Bohigas fue declarado Huésped de Honor, durante sus visitas a Rosario (Mateos, 2003) ${ }^{15}$.

Al capitán Cristiani le sucedió el dirigente del Partido Demócrata Progresista Alberto Natale, quien se desempeñó como Intendente hasta abril de 1983. Los recuerdos que tiene de dicha gestión el ejecutor de la obra del CCPE, Horacio Quiroga, no son de lo más amables:

\begin{abstract}
“...Al asumir el intendente Alberto Natale, las incipientes gestiones que llevaba adelante la Comisión Ejecutiva del Parque de España...encontró su más empecinado adversario.

Seguramente mal asesorado por su secretario de Planeamiento, Fernández Milani, se opuso tenazmente a colaborar en la gestión de la obra, quizá, seguramente, para distanciarse de su antecesor.

Recuerdo que, en la primera reunión con estas personas, Milani trajo una carpeta de archivo con una sola hoja en su interior: una nota de la Junta Nacional de Granos donde se comprometían a estudiar la donación de las tierras de su propiedad... En realidad no debe de haber sido exactamente así porque su antecesor, el Ing. Gurmendi le había encargado a su hijo (estudiante de arquitectura), y a un amigo, representados por el Arq. D'Angelo, el relevamiento de todas las tierras para que MBM pudiera hacer su anteproyecto, trabajo que debía necesariamente estar en algún lugar de la Secretaría”"
\end{abstract}

Jornadas de Estudios sobre Rosario y su Región. Viejos problemas, nuevas perspectivas. Universidad Nacional de Rosario, Rosario, Argentina, pp. 1. El subrayado es del original.

${ }^{15} \mathrm{El}$ arquitecto Fernando Boix recuerda que en esa época trabajaban junto a los arquitectos españoles en el Centro Cultural Bernardino Rivadavia (hoy Roberto Fontanarrosa) donde tenían un salón disponible para armar la documentación planimétrica "con mesas de 6 o $7 \mathrm{~m}$. de largo para poder dibujar los inmensos planos que se realizaban manualmente". (Brarda, A. 2012; op.cit.; pp. 92).

${ }^{16}$ Quiroga, Horacio. 2012; op.cit.; pp. 55. 
Es que las principales acciones desarrolladas por dicha gestión, no tuvieron su foco a diferencia de la anterior, urgida por presentar a Rosario como una ciudad moderna que sería sede del Mundial de Fútbol de 1978. En las grandes obras estructurales, la única importante fue el inicio del Acceso Ribereño Norte, el resto estuvo constituido por obras de repavimentación y ensanche de vías, siendo la gran preocupación en este período el crecimiento de los asentamientos irregulares o "villas de emergencia" (Mateos, 2003).

Distinta acogida con respecto a la ejecución de la obra del CCPE tuvo el Intendente Víctor Cabanellas (abril-diciembre de 1983), durante cuya gestión se suscribió finalmente un convenio con la colectividad española y el Gobierno de España para la realización del Parque, garantizando la posibilidad de un uso mixto (públicoprivado) del área de la costa (Mateos, 2003). Horacio Quiroga atribuyó en parte este cambio al parentesco del nuevo intendente con familias españolas distinguidas, que habitaron Rosario en las primeras décadas del siglo XX:

“...Las cosas empezaron a cambiar con la partida de Natale y el advenimiento de Cabanellas, que tuvo una especial actitud hacia el proyecto y hacia la propia colectividad, probablemente porque él también era descendiente de españoles, además ilustres, ya que uno de ellos fue Obispo de Valencia y una Cabanellas fue desposada por Francisco Roca y Simó, el gran arquitecto modernista, autor del Palacio Cabanellas, La Europea y el propio Club Español, entre otras obras [de la ciudad de Rosario]. Con Cabanellas se firmaron los primeros decretos y ordenanzas, cimientos de todo el aparato burocrático estatal"17.

El año 1984, puede ser considerado como el principio de la concreción real del proyecto del CCPE. En mayo el Comité Ejecutivo, acompañado por el Intendente de Rosario Horacio Usandizaga, el Embajador de España José Luis Messia Jiménez y miembros de todas las demarcaciones consulares, fue recibido en Buenos Aires por el presidente Raúl Alfonsín. El proyecto además contaba con los siguientes avales: declaración de interés nacional por parte de la Cámara de Senadores; declaración de interés provincial por el Poder Ejecutivo santafesino y declaración de interés municipal por el Concejo Deliberante de Rosario. (De Marco, 2012: 17-20). La reunión en Buenos Aires también fue clave para la cesión de terrenos del Estado Nacional que comprendían los muelles y parte de la franja costera donde funcionaba antiguamente el puerto de la ciudad. (Quiroga, 2012: 55).

El Comité Ejecutivo, con la adquisición de avales de todos los niveles gubernamentales y el terreno cedido a cargo para el emplazamiento del Parque, se decidió entonces a viajar a España, con el fin de interesar a su Gobierno y obtener

${ }^{17}$ Idem. 
financiación para concretar la obra. Antes de exponer las vicisitudes de los rosarinos en Madrid, es necesario poner nuevamente en contexto el relato, atendiendo a un artículo del investigador hispano-argentino Aníbal Iturrieta, que analiza la política cultural desarrollada por España hacia América Latina, en el período de la transición democrática de dicho país (Iturrieta, 1993). Las políticas culturales son entendidas por el autor como "el resultado de un complejo sistema de decisiones, actos y creaciones que compete al Estado, pero también a los actores sociales... la finalidad perseguida no es la cultura como mera vanidad intelectual de minorías, sino patrocinar empresas culturales que logren elevar el bienestar y la calidad de vida de una población"18. Numerosos agentes culturales de la transición española son señalados por este autor como fuertemente influyentes en los países de América Latina: diarios y revistas como "El País" o "Cambio 16"; la industria editorial y el cine, que recogía el cambio de actitudes de los sectores progresistas frente a la retirada del aparato represor y reflejaba el costumbrismo posmoderno de una Madrid abierta a los cambios y a la acogida de personas procedentes de diferentes lugares. Todos estos agentes desempeñaron un papel significativo, al difundir valores democráticos, el debate cultural y político europeo, dando lugar también a las expresiones literarias y ensayísticas latinoamericanas en momentos de crisis y autocensura de las editoriales de la región (Iturrieta, 1993: 188).

En mayo de 1984 arribó a la península el Comité Ejecutivo del Parque España, siendo recibidos el día 26 por el rey Juan Carlos en el Palacio de la Zarzuela. Los diez miembros del Comité estaban acompañados por los arquitectos Oriol Bohigas y Josep Martorell. La buena recepción del proyecto por parte del monarca contribuyó a cambiar el ánimo algo reacio que en un principio caracterizó a los funcionarios españoles, sucediéndose entonces una serie de reuniones con los ministerios de Asuntos Exteriores, Trabajo, Educación y Cultura, en el Instituto Español de Emigración. Finalmente el 30 de mayo, la administración española resolvió aprobar una inversión de 257 millones de pesetas para financiar los trabajos del Proyecto (De Marco, 2012: 20). Los funcionarios ibéricos y la delegación rosarina firmaron ese día una "Carta de Intención", tendiente a la puesta en funcionamiento y gestión del Comité Ejecutivo de Parque de España, que cuenta con los siguientes ítems:

“ $1^{\circ}$ ) El Ministerio de Asuntos Exteriores a través del I.C.I. [Instituto de Cooperación Iberoamericana] ofrece, alternativamente, la cantidad de doce millones de pesetas, en dos años...o la de quince millones, en cuatro anualidades.

$2^{\circ}$ ) El Ministerio de Educación y Ciencia y el Instituto Español de Emigración, en proporciones iguales, se comprometen a financiar la construcción del Centro Educativo, hasta un total de ciento ochenta y dos millones de pesetas, en cuatro anualidades, a partir de 1985.

\footnotetext{
${ }^{18}$ Iturrieta, Aníbal. 1993. "De la transición democrática al Quinto Centenario (1975-1991)”. En: Pedro Pérez Herrero y Nuria Tabanera (coord.) España / América Latina: un siglo de políticas culturales. Madrid, AIETI/Síntesis-OEI, pp. 181-182.
} 
$3^{\circ}$ ) El Ministerio de Cultura compromete su aporte para la construcción de los cuatro Túneles de Exposiciones y Conferencias...La aportación se cifra en sesenta millones de pesetas en cuatro anualidades, a partir de 1985.

$4^{\circ}$ ) La Comisión Nacional del V Centenario ha resuelto que el Centro Cultural Parque de España integre con carácter preferencial el programa que conmemore los cinco siglos del descubrimiento de América.

$5^{\circ}$ ) Para la gestión de la construcción y del funcionamiento posterior del Complejo Cultural Parque de España, se constituirá una fundación cuyo cuerpo directivo estará compuesto por: a) Miembros que representen a los distintos Organismos de la Administración española que participen en el proyecto; b) Miembros que representen a la colectividad española en Rosario, y a las Federaciones de Entidades españolas en la Argentina u otros países del área; c) Miembros de la comunidad argentina, a nivel institucional o personal.

$6^{\circ}$ ) Los Estatutos, y la modificación de los mismos, de la Fundación 'Complejo Cultural Parque de España' deberán ser aprobados por la administración española.

$7^{\circ}$ ) Los terrenos sobre los cuales se construya el complejo cultural y los edificios que lo integran serán de propiedad del Estado español, que establecerá oportunamente la forma y el tiempo de instrumentar dicho derecho.

$8^{\circ}$ ) La Comisión Ejecutiva del Complejo Cultural Parque España y la Federación de Asociaciones Españolas de la Provincia de Santa Fe...manifiesta que existe aporte de la colectividad española de Rosario de setecientos mil dólares, con el cual se ha pagado el proyecto general básico y los proyectos ejecutivos, así como la gestión y el desarrollo de esta obra, que se inició en 1977. Así mismo expresan que la contribución de la Ciudad de Rosario, a través de su Municipio, se realizó al ceder catorce hectáreas de terreno sobre el río Paraná...”19.

Una vez más, los recuerdos de Horacio Quiroga, nos permiten acercarnos a las sensaciones y a los ánimos vividos por la delegación rosarina en su estancia en Madrid:

“...A pesar de los avisos cursados por la Embajada, no nos recibía nadie. Recuerdo una sola reunión en el Palacio de la

\footnotetext{
${ }^{19}$ Reproducido en De Gregorio, Roberto; Mesanich, Susana y Sánchez, Ana María. 2012. Complejo Cultural Parque de España, Rosario, s/e, pp. 13. En esta carta de intención se consigna además la adhesión prestada por las Federaciones de Entidades Españolas de Buenos Aires, Córdoba, Mendoza, Bahía Blanca y Santa Fe.
} 


\begin{abstract}
Santa Cruz, en la Dirección de Asuntos Consulares, con su director, Pastor Ridruejo, curiosamente devenido embajador en Buenos Aires en ocasión de la inauguración del Complejo. De todas maneras, creo que por el sonar de las puertas golpeadas, la cosa llegó a oídos del Marqués de Mondejar, Jefe de la Casa Real y en poco tiempo más encontramos una invitación a visitar a SM el Rey en la Zarzuela para presentar el proyecto...La visita al Rey produjo un vuelco espectacular en la gestión...”20.
\end{abstract}

De esta primera incursión de los rosarinos en la península (habrá otro viaje en 1987), podemos concluir que existía una importante dosis de desconfianza o desinterés hacia el Proyecto Parque de España por parte de los miembros de la burocracia española, y que en definitiva el mismo obtuvo recién legitimidad ante ellos, a partir de la acogida otorgada por el rey Juan Carlos. El artículo ya citado de Aníbal Iturrieta, nos ofrece pistas para comprender el por qué de estas disímiles actitudes. Por un lado afirma que la herencia colonial seguía pesando en España, aún en momentos de la Transición, a la hora de definir sus relaciones con nuestro continente: “...Del sentimiento de culpabilidad histórica, proveniente de la acción depredadora de la conquista, de los paternalismos históricos del imperio cultural hispánico, se pasa rápidamente a la soberbia del nuevo rico moderno y europeo, con la que algunos decidores, intelectuales y políticos manejan, con resquemores y altisonancias, la política cultural hacia América Latina" (Iturrieta, 1993: 188). En contraste con estos sectores, la institución monárquica es la que se perfila, en la persona de Juan Carlos, como la gran promotora de la incentivación de las relaciones culturales entre españoles y americanos; actitud que comenzó a manifestarse claramente desde 1976, a través de viajes, actos y discursos. El 12 de octubre de ese año, en Cartagena (Colombia) "estableció los principios de solidaridad, de cooperación mutua, de interdependencia, de mejora de la calidad de vida y el proyecto de constitución de una familia de naciones a través de la formación de la Comunidad Iberoamericana"; proyecto que tuvo su origen en el régimen franquista, bajo la denominación de Comunidad Hispánica, pero que el renovado discurso de la monarquía limó de resabios imperiales, planteando relaciones bilaterales en un plano más igualitario, destacando "lo poco comprensible que resultaría España, histórica, social y culturalmente, sin su vertiente americana, a la vez que afirmaba el principio de credibilidad como forma de abandonar una política declarativa y lírica" (Iturrieta, 1993: 197).

La visita de los reyes Juan Carlos y Sofía a Rosario, el 17 de abril de 1985, resultó un acto más de afirmación de estos renovados aires en la política cultural exterior de la península, y por supuesto, un espaldarazo definitivo para la ejecución de la obra del CCPE; comprometiendo de cierta forma a las autoridades argentinas (locales, provinciales y nacionales) en la materialización de la misma. En un evento que contó con un masivo recibimiento, las autoridades presentes descubrieron una placa

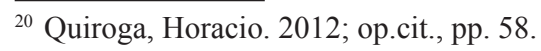


en el actual predio del Parque de España y anunciaron oficialmente la iniciación de los trabajos de edificación del Complejo, que deberían culminar en el año 1992.

Las labores sobre el predio, coordinadas por el estudio de arquitectura de Horacio Quiroga, contaron con la colaboración de los ingenieros Yuffre y Rubinstein, a cargo del diseño y cálculo de la estructura, y de los ingenieros Torres y Vercelli, que tuvieron a su cargo el estudio de los suelos. Ya en los primeros meses de 1986 se llamó a licitación para la ejecución de la estructura de hormigón armado y metálica, siendo beneficiada la empresa GESIE-MES SACIFI, de Buenos Aires; mientras que la licitación para la instalación eléctrica favoreció a una empresa local Electrosur S.A. Los avances de las mismas obligaron a reformular parcialmente los proyectos y diseños originales. Así, al avanzar en el estudio de la obra se vio la necesidad de ejecutar toda la estructura sobre pilotes, y con la terminación de la estructura, prácticamente también se terminaron los fondos asignados, que sufrieron además los avatares de la inestable economía argentina del momento ${ }^{21}$ (Quiroga, 2012: 62-65).

Así las cosas, el Comité Ejecutivo del Parque de España debió viajar nuevamente a Madrid en 1987, para explicar la delicada situación financiera en que se hallaba la obra22. Horacio Quiroga realiza un paralelo con el viaje de 1984, enumerando los cambios que percibió en la recepción de los funcionarios españoles:

“..Emblemática fue la circunstancia que en vez de una gran mesa redonda, esta vez habían dispuesto una mesa anular, con aire en el medio y audio para cada expositor. Cuando nos invitaron a comer, también fue significativo el menú: pisto manchego, que vendría a ser lo más barato y más representativo de la comida popular del campo español: una mezcla de verduras baratas...

El jefe de la delegación [española], un tal Angulo...era lisa y llanamente partidario de abandonar la obra, paralizarla y adiós...En definitiva, después de tomar conciencia que verdaderamente era peor dejar abandonada la estructura que soportar el dolor de la derrota a manos de unos inmigrantes patoteros como creo que deben haber pensado de nosotros, se decidió terminar con la obra con las siguientes condiciones:

\footnotetext{
${ }^{21}$ El mismo Quiroga relata que "nuestros amigos españoles nunca llegaron a entender por qué les mandábamos toneladas de papeles incomprensibles. Y en rigor de verdad, las cifras eran dibujos de la supuesta economía, ya que había un primer certificado provisorio que daba un resultado, después aparecía uno definitivo, ya con el índice de inflación oficial. Si por casualidad, llegaba a darse un aumento de salarios aparecía un tercer certificado. Todo eso era enviado por octuplicado...por valija diplomática y, sí, resultaba comprensible que los españoles no entendieran nada de todo esto ya que para saber cuanto les había costado una obra a ellos les bastaba con sumar las facturas. No conocían las emociones de la inflación". En Quiroga, Horacio. 2012; op.cit., pp.65.

${ }^{22}$ Los integrantes de la delegación, quienes corrieron con los gastos del viaje, fueron: Gerardo Hernández, Horacio Quiroga, Jesús Azanza, Sandalio Monreal, Teófilo Espadas, Horacio Castaño, Gregorio Lizarbe y Vicente Suárez Fernández.
} 


\begin{abstract}
El Colegio a realizarse no iba a ser para el existente Colegio Español de Rosario (en adelante CER), ya que no se veía la razón por la cual la Fundación... debía regalarle a una Asociación Civil propietaria del CER semejante edificio. Más bien prefirieron ajustarse a los Colegios españoles de exportación, adoptando el modelo del de San Pablo, Brasil...Se eliminaban todos los institutos que se pensaban instalar allí: desaparecieron de un plumazo: la universidad a distancia, el Centro de Estudios Iberoamericanos y la Biblioteca Hispánica y naturalmente los túneles, lo que evidenciaba el predominio de la financiación del Ministerio de Educación y Ciencias, sobre los otros ministerios..." ${ }^{23}$.
\end{abstract}

Los españoles designaron un Administrador, Juan Francisco Poblador Fuentes, con mandato para coordinar todas las acciones tendientes a la financiación de la obra. Dicho funcionario fue permeable a las insistencias de los miembros del Comité Ejecutivo en torno a la necesidad de incluir el acondicionamiento de los túneles, para que el Complejo incluya también a las galerías donde se desarrollarían las actividades culturales. En un programa radial matutino, que contaba con gran audiencia, un popular comunicador, Evaristo Monti, había emprendido una verdadera campaña de desprestigio de la obra, afirmando día a día que se habían otorgado los mejores terrenos de la ciudad a un colegio español privado. Poblador viajó a Madrid y logró que se incluyeran los túneles en el edificio, asegurándose así el funcionamiento del Centro Cultural. Otra de las condiciones impuestas desde la península fue que la obra la terminara una empresa española DYCASA Construcciones, subsidiaria de Dragados y Caminos de España. Para mantener el precio pactado en 1987 por la obra se modificaron las exigencias de los arquitectos de adquirir algunos productos costosos, aceptando otros iguales pero de menor precio e igual cantidad, con lo que se logró mantener un buen clima de trabajo ${ }^{24}$. (Quiroga, 2012: 68-69).

Finalmente, el 28 de noviembre de 1992, se realizó el acto inaugural del CCPE. Estuvieron presentes el presidente Carlos Menem, el gobernador Carlos Reutemann y el Intendente Héctor Cavallero, además de otros funcionarios que representaron a las autoridades nacionales. España estuvo representada esta vez por la Infanta doña Cristina, quien se entusiasmó con la muestra de pintores rosarinos curada por Pedro

\footnotetext{
${ }^{23}$ Quiroga, Horacio. 2012. op.cit., pp. 65-68.

${ }^{24}$ El arquitecto encargado del proyecto ejecutivo apunta también la contribución de los obreros a la misma, que en sus últimos tramos, se cobró una vida: "Casi al finalizar la obra tuvimos una tremenda desgracia. Un joven operario murió al derrumbarse tierra floja en una zanja para cloaca. La zanja era de sólo 1,60 mts. de profundidad y aún hoy día se me hace difícil creer que murió asfixiado. Tengo para mí y quizá me sirva de consuelo, que un paro cardíaco debe de haberlo matado ante el tremendo susto del derrumbe. La obra se cubrió, verdaderamente, de un manto de pena que duró varios días. La Empresa asistió a la familia generosamente, pero aún es un mal recuerdo que cada tanto me entristece.” (Quiroga, Horacio. 2012. op.cit., pp. 69).
} 
Sinópoli, en los túneles del Centro Cultural. Por la noche, se ofreció un concierto en el Monumento Nacional a la Bandera, a cargo de la Orquesta Sinfónica Nacional y el reconocido tenor Alfredo Kraus. ${ }^{25}$

El canciller del Consulado General de España en Rosario, Gerardo Hernández Illanes, precursor y tenaz promotor de la obra, expresó la importancia del acontecimiento en una gacetilla de prensa, con las siguientes afirmaciones:

"Desde aquel 1977 en que soñamos con la posibilidad de construir en el Parque de España un Complejo Cultural y Educativo, hasta esta realidad que culmina hoy, 28 de noviembre de 1992, han pasado no sólo quince años, sino un cúmulo de esfuerzos, ilusiones, alegrías y también sinsabores.

Esta obra es el fruto de mucha gente que creyó que todavía es posible pensar en grande, generar en esta ciudad de Rosario un proyecto de nivel internacional.

Es fruto también del nuevo sentido de la hispanidad, que supera la mera concepción dialéctica para insertarse en el campo de los hechos y las realizaciones. El Colegio Hispano-Argentino, la UNED, las salas de exposiciones y conferencias, la biblioteca, el teatro y el anfiteatro, son el hecho evidente de una actitud nueva que se cimenta en la cooperación y la integración iberoamericana.

Los españoles que aquí residimos cumplimos un doble sueño. Mantener viva la presencia de España y realizar un acto de servicio y de agradecimiento a esta tierra argentina. Esto ha sido posible porque tanto la administración española, como la $\mathrm{Mu}-$ nicipalidad de Rosario y la colectividad española, han sumado su esfuerzo en una obra común que conmemora el Descubrimiento con un proyecto de futuro" ${ }^{26}$.

\footnotetext{
${ }^{25}$ La prensa local y también la nacional cubrieron de manera extensa el acontecimiento. Se puede consultar para ello los siguientes diarios: La Nación, Buenos Aires, 27 de noviembre de 1992, pp. 18; Rosario 12, Rosario, 29 de noviembre de 1992, pp. 2-4; La Capital, Rosario, 28 de noviembre de 1992, pp.1-8 y Suplemento Especial $3^{\text {a }}$ Sección.

${ }^{26}$ Hernández Illanes, Gerardo. 1992. "Nota del canciller del Consulado de España”. En La Capital, sábado 28 de noviembre de 1992, $3^{\text {a }}$ sección, pp. 7. Los avisos de adhesión al acto inaugural del CCPE dan cuenta del amplio espectro de instituciones y empresas que acompañaron la ejecución de esta obra. A continuación ofrecemos un listado de las mismas: Honorable Concejo Municipal de Rosario, Cámara de Diputados de la Provincia de Santa Fe, Banco Monserrat, Gafa, La Gallega Supermercados, Telecom Argentina, Canal 3 Rosario, Rosarios Refrescos S.A., Cafés La Virginia, Cámara de Supermercados, Fábrica de Aceites Santa Clara, Fiambres Paladini, Hipermercado Tigre, Canal 5 Rosario, Ministerio de Cultura y Educación de la Nación (Secretaría de Cultura), Banco Municipal, Banco de Santa Fe S.A., Banco Israelita, Banco Popular Argentino, Sanso Turismo, Baron Sport, Aciso Banco Cooperativo Ltdo., Ing. Pellegrinet S.A., Segurometal, La Montevideana, Austral Líneas Aéreas, Bolsa de Comercio de Rosario, Audio Ingeniería S.R.L., Cámara de Almaceneros de Rosario, Adriana de Saccone (diseño de espacios verdes), Rassegna S.R.L. (amoblamientos), Cormela S.A.(cerámicos), Moltrasio (mosaicos),
} 


\section{Excurso: Un lugar para la Historia}

En el proyecto original, mentado por Gerardo Hernández Illanes, estaba contemplado "traer el Archivo de Indias" a Rosario, microfilmación mediante, para permitir que los investigadores argentinos y de todo el Cono Sur pudieran consultarlo en las instalaciones del Complejo. El Canciller del Consulado español en Rosario se había inspirado en un artículo publicado en el diario madrileño $A B C$, por el ex embajador de España en la Argentina José María de Areilza, que propuso que su país donase a las naciones americanas una colección microfilmada de los fondos del repositorio sevillano, con motivo del V Centenario del Descubrimiento de América. Para ello convocó a un reconocido historiador local, formado en la Universidad Católica Argentina de Rosario y miembro de número de la Academia Nacional de la Historia, Miguel Ángel De Marco. Su primera tarea fue preparar un informe, que el Comité Ejecutivo del Parque de España iba a presentar en Madrid en 1984, en el que se señalaba que a pocos kilómetros del sitio donde se erigiría el Complejo, se había alzado el Fuerte de Sancti Spiritus, primer enclave español en el Río de la Plata. De esa manera el Comité contaría con un elemento más para convencer a los españoles de acompañar la construcción de la obra cultural en Rosario, la única ciudad del país surgida antes del siglo XIX, que no había contado con un acto fundacional según las reglas hispanas (De Marco, 2012: 14-17).

De esta manera, y como parte integrante del CCPE, nació el Centro de Investigación y Documentación Histórica (en adelante CIDH). Durante el año 1987, inició sus tareas con el apoyo del Instituto de Cooperación Iberoamericana. Luego de conversaciones con especialistas de España y América, particularmente con la directora del Archivo General de Indias de Sevilla, se decidió realizar un relevamiento de archivos argentinos, para luego informatizar los resultados, de manera de poder ofrecerlos a los investigadores que se interesen en ellos. También se propuso microfilmar los documentos complementarios en los repositorios metropolitanos o de otros países latinoamericanos. Los repositorios argentinos que se relvaron en este primer momento fueron: Archivo del Ministerio de Relaciones Exteriores de la República Argentina, Archivo General

Miller (iluminación), Guillermo Luis Beutke (obras de ingeniería), Cooperativa Minera de Arena de Rosario Ltda., Madetec S.A.(maderas y revestimientos), Sorrento (máquinas, equipos y elementos para la construcción), Ascensores Hidral, Cerámica Alberdi S.A., Previnca (seguros), Servicios Caramuto (casa funeraria), San Nicolás Compañía de Seguros S.A., Hugo Turra (fábrica de monolitos), Gesiemes (constructora, inmobiliaria y agrícola ganadera), E. Menchón (transportes especiales), Haidar Construcciones, Antonio Teresa y Russo (excavaciones, pavimentaciones), Tessarolo Hnos. (construcciones sanitarias), Compañía González S.A. Seguridad Industrial, Osvaldo Di Pietro (transportes volcadores), Indupor (polietileno), Motivo (alfombramientos), Impulsar (bombas sumergibles), Tecno Obras (impermeabilizaciones), La Luna (parques y jardines), Luis Luzzi (agua, cloaca, gas), Hormicen (hormigón elaborado), Alzua (arenas), Vittorio (telas y papeles), Grúas Transportes S.R.L., Instituto Gamma (clínica de diagnóstico), La Reina Supermercados, Ondemar (amortiguadores), Pinturas Suvinil, Ifestos (establecimiento metalúrgico), King Way (permisionario Encotel), Cepreme S.A. (prestaciones médicas), Transportes La Sevillanita, Cormetal (chapas), Isaura (estación de servicio), Yeso Tuyango, Banco Santafesino de Inversión y Desarrollo S.A., Expreso Ben Hur (compañía de transportes), Expreso Emir, Dycasa, Luraschi (hormigón armado), Electrosur S.R.L., Hidrolimp (hidrolavados), Supintura. (En: Sin Autor. 1992. "Complejo Cultural Parque de España"; La Capital, Rosario, sábado 28 de noviembre de $1992,3^{\text {a }}$ sección, pp. 1-8) 
de la Nación (series Aduanas de Buenos Aires y Montevideo) y Archivos Generales de las Provincias de Santa Fe y de Corrientes. Respectivamente, estuvieron a cargo de las tareas (volcadas en minuciosos informes) Isidoro Ruiz Moreno ${ }^{27}$, Alberto David Leiva ${ }^{28}$ y Beatriz Figallo ${ }^{29}$. Se esperaba continuar con estas tareas en 1988, pero el cese del financiamiento español detuvo el proyecto (De Marco, 1988) ${ }^{30}$.

Habrá que esperar prácticamente una década para que el espacio reservado a la Historia dentro del CCPE tuviera nuevamente un desarrollo dinámico. En 1997, la historiadora Carina Frid presentó el Proyecto Área de Investigación y Documentación Histórica Parque de España. Los ejes fundamentales de la propuesta se centraron en la investigación histórica iberoamericana y el uso de tecnologías asociadas a la preservación de documentación histórica. En el Informe de Avance del Proyecto se detallan los contactos emprendidos con centros e instituciones académicas ${ }^{31}$ y las posibles fuentes de financiamiento para el desarrollo de los objetivos propuestos ${ }^{32}$. En el

${ }^{27}$ Profesor de Historia de la Universidad de Buenos Aires y en la Escuela Superior de Guerra, presidente del Instituto Histórico de la Organización Nacional y miembro de la Academia Sanmartiniana

${ }^{28}$ Miembro correspondiente de la Junta Provincial Histórica de Santa Fe y fundador del Instituto Investigaciones Históricas del Derecho

${ }^{29}$ Profesora y licenciada en Historia por la Universidad Católica Argentina y doctora en Historia por la Universidad Complutense de Madrid.

${ }^{30}$ En el Boletín que informa acerca de las actividades del CIDH también se consigna la donación de material bibliográfico por parte de diversas instituciones nacionales y extranjeras para la biblioteca; así como la edición de un libro de autoría de su director, Miguel Ángel De Marco, titulado Argentinos y Españoles. (De Marco, Miguel Ángel. 1988. Boletín Informativo. Año I. Noviembre de 1988. $\mathrm{N}^{\circ}$ 1, Rosario, Fundación Complejo Cultural Parque España. Centro de Investigación y Documentación Histórica).

${ }^{31}$ Instituto de Historia Argentina y Americana "Dr. Emilio Ravignani" (Facultad de Filosofía y Letras. Universidad de Buenos Aires); Centro de Estudios Migratorios Latinoamericanos CEMLA (Buenos Aires); Universidad de Oviedo; Universidad Internacional de Andalucía (Sede La Rábida); Instituto Universitario Ortega y Gasset (Madrid); Ibero-Amerikanisches Institut (Berlín); Consello da Cultura Galega / Archivo de la Emigración Gallega (Santiago de Compostela); Instituto de Estudios Sociales y Políticos IDESP / Universidad de San Pablo; Balch Institute / Temple University, Philadelphia; Università degli Studi di Bologna; Universidad de la República (Montevideo); Escuela de Historia, Facultad de Humanidades y Artes, Universidad Nacional de Rosario;Vicerrectoría de Relaciones Internacionales de la Universidad Nacional de Rosario; Organización de Estados Iberoamericanos; Biblioteca Nacional de España / ABINIA. Todos estos datos fueron consignados en el Informe Preliminar del Proyecto Área de Investigación y Documentación Histórica Parque de España, presentado por la Lic. Carina Frid de Silberstein en Diciembre de 1997, y que se encuentra en el Archivo del CEHIPE.

${ }^{32}$ Se realiza un detallado informe de las instituciones que fueron contactadas y de las propuestas realizadas: UNESCO (proyecto de participación en un concurso, presentado como tema "Las Misiones Jesuíticas como patrimonio mundial: informatización de los archivos documentales atingentes a las Misiones Jesuíticas"); Banco Interamericano de Desarrollo BID (pedido de un crédito de cincuenta mil dólares para capacitación tecnológica para la administración de imágenes digitalizadas de documentos históricos; Oficina Tecnológica de Cooperación (proyecto de cooperación para la capacitación tecnológica, formación de recursos humanos y asesoramiento especializado en el área de la historia iberoamericana); Fundación Tavera, dedicada a la preservación de material documental relativo al período hispánico y al desarrollo de tecnologías digitalizadas de catalogación y documentación (convenio para la digitalización de las Actas Impresas de Cabildos Iberoamericanos, ha provisto al Centro de versiones digitales en CDRom del Archivo del Museo Naval de Madrid y de 246 obras impresas de la Colección Mapfre 1492); Consejo Nacional de Investigaciones Científicas y Técnicas CONICET; Secretaría de Ciencia y Técnica 
primer informe de gestión elaborado por la ahora directora, Carina Frid ${ }^{33}$, se da cuenta de las instituciones y personas que hicieron posible la labor del Área: la Municipalidad de Rosario ${ }^{34}$, D. Vicente Rodríguez ${ }^{35}$, el Dr. Gerardo Hernández Illanes y la Fundación Antorchas ${ }^{36}$.

Durante el año 1998 se inició el Proyecto de Recuperación de la Prensa Periódica Rosarina (1850-1900), que fue el primer emprendimiento sistemático de preservación de fondos documentales pertenecientes a bibliotecas públicas en el país, mediante la técnica de microfilmación. La marcha del mismo fue monitoreada por la Fundación Antorchas y el Library College de Harvard, dirigido por Dan Hazen. Este fue el inicio de una exitosa experiencia de conservación y preservación documental que provocó sinergias entre el Área y numerosos archivos, bibliotecas, hemerotecas y universidades de distintos puntos del país, sistematizado a partir del año 2005 a través de la convocatoria anual a concursos para subsidios de microfilmación y digitalización de fondos escritos y fotográficos ${ }^{37}$.

Un hito fundamental del Área fue la inauguración del Archivo de Microfilms e Imágenes Documentales y de la Sala de Consultas y de Control de Calidad en agosto de $2000^{38}$. Cabe mencionar que a partir del año 2001 el Área adquiere el carácter de

del Ministerio de Producción de la Provincia de Santa Fe; Fundación Antorchas, que conforma el modelo más profesionalizado en el otorgamiento de subsidios a la investigación básica en Argentina; A. Mellon Foundation, una de las principales instituciones dedicadas a promover la preservación documental a escala internacional; Fundación Ramón Areces, ha iniciado la catalogación e informatización de colecciones documentales correspondientes al Archivo de Indias de Sevilla; Fundación Archivo de Indianos, de Colombres, Asturias, que ha centrado su actividad en la constitución de un Centro de Documentación y de Estudios sobre la Emigración Española a América; Fundación para el Desarrollo del Conocimiento FUNDESCO, que estudia los efectos económicos y sociales de las tecnologías de la información y la comunicación dentro del marco iberoamericano. Todos estos datos fueron consignados en el Informe Preliminar del Proyecto Área de Investigación y Documentación Histórica Parque de España, presentado por la Lic. Carina Frid de Silberstein en Diciembre de 1997, y que se encuentra en el Archivo del CEHIPE.

${ }^{33}$ Egresada como Profesora en Historia de la Facultad de Filosofía y Letras de la UBA, Máster en Historia por la Universidad de Calgary (Alberta, Canadá) y Doctora Interuniversitaria en Historia por las Universidades Nacionales del Centro de la Provincia de Buenos Aires y de Mar del Plata. Con actividades docentes en la Universidad Nacional de Rosario, la Cátedra Jovellanos de la Universidad de Oviedo (España), el Istituto sull'Economia del Mezzogiorno de la Universidad de Nápoles (Italia). Cuando asumió la dirección ya se desempeñaba como investigadora en el CONICET. Sus publicaciones -hasta ese momento- se enfocaban primordialmente en temas de la historia de las migraciones (con mayor énfasis en la colectividad italiana; su tesis de Maestría se titula "Gringos at the Gate of the Pampas: Italians in Rosario, 1870-1914". (El currículum completo puede verse en el Informe Preliminar ya citado, Anexo s/p).

${ }^{34}$ Otorgó un subsidio de $\$ 16.000$ para la preservación de la prensa local .

${ }_{35}^{35}$ Donó u\$s 10.000 para la instalación y equipamiento de la entidad.

${ }^{36}$ Otorgó una ayuda financiera de $\$ 16.700$, también para preservar la prensa periódica local.

${ }^{37}$ Estos concursos anuales reúnen el apoyo financiero de la Fundación Antorchas, de la Agencia Española de Cooperación Internacional y Desarrollo (AECID), de la Fundación Bunge y Born, del Programa para Bibliotecas y Archivos Latinoamericanos con sede en la Universidad de Harvard (PLALA) y del Latin American Microform Project (LAMP).

${ }^{38}$ A partir de ese año la institución ofrece servicios de custodia y conservación no sólo de películas originales y de copias de reproducción, sino también de aquellos formatos que requieren de condiciones 
institución autónoma dentro del CCPE, adquiriendo así un nuevo nombre: Centro de Estudios Históricos e Información Parque de España (en adelante CEHIPE). La labor de apoyo y difusión a la producción historiográfica no ha sido opacada por las de conservación y preservación documental. Así, se organizaron cursos, jornadas y congresos que reunieron a prestigiosos historiadores e investigadores de la ciudad, del país y del exterior y se radicaron en la institución diversos proyectos de investigación ${ }^{39}$.

\title{
Conclusión: Impacto urbanístico del Complejo Cultural Parque de España
}

En una entrevista realizada a Oriol Bohigas en un viaje en barco por el río Paraná, desde donde se podía apreciar la obra, ya finalizada, del Parque de España, se le interrogó de que manera influyeron las imágenes de Barcelona en el proyecto por él diseñado para Rosario. Esta fue su respuesta:

\begin{abstract}
"No. Yo creo que es al revés. Hay experiencias de Rosario que luego se han aplicado a Barcelona. Esta preocupación de la apertura de la ciudad al río o al mar yo creo que nuestro estudio empezó en Rosario y luego las ha concretado no solo en Barcelona, sino en otras ciudades. Es una línea que aquí se intuyó prematuramente, pero en este momento es la preocupación de todas las ciudades. Los límites entre agua y tierra han sido ocupados por cosas secundarias como el ferrocarril, las industrias obsoletas, y a medida que esto ha sido definitivamente obsoleto las ciudades han tenido ocasión de recuperar este contacto con el mar o río, con el agua, cosa que es apoyada por la nueva cultura de la forma de vivir" ${ }^{40}$.
\end{abstract}

Es así que el CCPE puede considerarse una "obra bisagra", comparable con la construcción del puerto nacional en la primera década del siglo XX. Ese fue un

\footnotetext{
ambientales de estabilidad para su conservación. La climatización del Archivo del Parque de España hace posible que los mismos sean guardados a una temperatura estable $\left(18^{\circ}\right.$ a $\left.21^{\circ}\right)$ y a una humedad relativa del 35\% (+/ - 5\%). Los rollos de microfilm han sido alojados en gabinetes especiales con estanterías móviles y conservados en cajas libres de ácido. El espacio asignado al depósito del material microfilmado cuenta con las medidas preventivas necesarias para garantizar la exclusión de agentes de polución y de niveles de contaminación ambiental, así como de incendios, manipulación inadecuada y posibles averías y roturas (Fundación Complejo Cultural Parque de España. Área de Investigación y Documentación Histórica Parque de España. Informe de Actividades Año 2000, s/p).

${ }^{39}$ El CEHIPE cuenta con una página web que da cuenta de sus prolíficas actividades tanto en el campo historiográfico como en el de la preservación documental; de los importantes fondos bibliográficos y documentales que posee en su biblioteca y de los servicios que presta a la comunidad de investigadores profesionales y público en general interesado por la Historia. Ver http://www.cehipe.org.ar/nuevositio/ Aprovecho aquí también para dejar constancia de la predisposición presentada por la directora del CEHIPE, Doctora Carina Frid y sus demás integrantes, Profesor Marcelo Mariani y los señores Julián Gómez y Pablo Valenta, a la hora de facilitarme documentación perteneciente a la institución, para poder realizar éste artículo.

${ }^{40}$ Sin Autor. 1994. "El primer paso..." En: El Cronista. Arquitectura, Buenos Aires, 18 de mayo, pp. 3-11. Los subrayados son nuestros.
} 
momento de conflictos, de desarrollo y transformación al mismo tiempo. El Parque de España generó lo mismo en la ciudad ${ }^{41}$, dando el puntapié inicial para la renovación del área costera central que hoy disfrutan los rosarinos. (Brarda, 2012: 95). Constituyó, desde finales de la década de 1970, una suerte de "señal de largada" del proceso de transformación urbana que Rosario viene llevando a cabo en su frente fluvial desde hace más de veinte años, y que a su vez se asienta sobre consensos técnicos y sociales construidos durante varias décadas previas. Dicho proceso de reflexión y proyección sobre la ciudad y para la ciudad iniciado, por lo menos, en la tercer década del siglo XX y en el que se reconocen como momentos centrales el trabajo de la Comisión Nacional, la formulación del Plan Rosario y la sanción del Plan Regulador de 1967 condujo a un acuerdo básico en relación al destino de la costa central: ésta no debía ser lugar ni de la actividad portuaria ni de la ferroviaria, sino lugar de actividades recreativas y culturales. (Floriani, 2012: 98)

Nos parece apropiado finalizar estas conclusiones con las palabras autorizadas de arquitectos y arquitectas rosarinas, que además de describir el espacio propiamente dicho conformado por el CCPE en la ciudad, también destacan los valores con los que desde el punto de vista patrimonial, cultural, simbólico y social, dota a la misma:

"El CCPE, desde su inauguración en 1992, se identifica en la ciudad no solamente por su complejidad volumétrica y su expresión simbólica, sino por su emplazamiento, su especial modo de respetar el entorno, la naturaleza de la barranca, y su cuidado de no interferir visuales desde la ciudad hacia el río Paraná. Cabe destacar lo excepcional de esta construcción en

\footnotetext{
${ }^{41}$ Hemos consignado líneas más arriba, la campaña de desprestigio sufrida por la obra en una emisora radial de la ciudad de Rosario. Algunas críticas se hicieron oír aún después de finalizada la obra, como ésta, de ácida redacción, publicada en un matutino porteño antes de cumplirse el primer aniversario de la inauguración: “A casi un año de la inauguración del CCPE... el funcionamiento del mismo es casi inexistente. Si bien ....alberga ya a los alumnos secundarios del Colegio Español ...el gran espacio construido para la actividad cultural funciona a cuentagotas... Los cinco túneles destinados a muestras, exposiciones y eventos culturales han abierto de vez en cuando. Lo lógico y lo prometido, fue el desarrollo de una actividad permanente. Al no ser así, tampoco se puede cumplir con uno de los objetivos más proclamados durante la construcción: el acceso libre al complejo... El primer inconveniente surgido fue económico. Desde España se ha avisado que no se pondrá una peseta más para este proyecto, y en Rosario no se hace sencillo recaudar fondos. En la Comuna también hay diferencias de criterios, entre los que entienden que se debe ofrecer cierto nivel de cultura, de acuerdo a la categoría del complejo, y los que apuntan a popularizarlo. Y más allá de esta cuestión conceptual sobre qué cultura hacer, hasta la propia colectividad ha entrado en internas. Como anécdota ha quedado el espacio de una placa en el colegio con los nombres de algunos 'ilustres' que ayudaron a la realización de la obra, que en la misma noche de su colocación fue retirada, aparentemente por aquellos que también se sintieron 'ilustres' pero no aparecieron en la nómina. Y por si faltara algo, la vista del complejo no es la mejor. La carencia de seguridad posibilitó que desaprensivos rompieran o dañaran muchas instalaciones, y la empresa de cerámica rosarina que vendió los cerámicos tendrá que dar explicaciones de por qué contienen tanto salitre, hecho que le da un aspecto ruinoso." (Brisaboa, Jorge. 1993. "El parque España no funciona". En: Clarín, Buenos Aires, lunes 16 de agosto, pp. 41).
} 
el hecho de plantear una unión perfectamente expresada entre lo viejo -los túneles-, y lo nuevo, el edificio... al pie de la barranca.

Todo el edificio se brinda hacia el Paraná, con una longitud de fachada de 175m., que 'abraza' la barranca, en el inicio, con las escaleras y columnas, y finaliza cerrando con el volumen del teatro. Se destaca la generación del espacio denominado 'Patio de los Cipreses' que se presenta como una transición entre lo viejo y lo nuevo, un espacio a cielo abierto, pero 'adentro' del conjunto de cuatro niveles que alojan aulas y espacios destinados a administración, biblioteca, y salones especiales del Colegio; locales para el Centro de Estudios Históricos y la Fundación Complejo Cultural Parque de España, así como los Túneles transformados en Salas de Exposición, Administración y Biblioteca del Centro Cultural...

Esta obra arquitectónica tiene valor histórico porque hechos relevantes han ocurrido en sus espacios: la visita de los Reyes de España, la Infanta, numerosos académicos internacionales, artistas locales, nacionales e internacionales...

Asimismo posee valor cultural: porque está presente en las innovaciones o particularidades en los modos de producir y en las soluciones aplicadas a problemas de diseño o construcción. Es un documento que a través de una correcta lectura, nos permitirá en el futuro conocer el pasado.

Puede agregarse un valor simbólico-social: porque sirve a una sociedad: todo el área metropolitana de Rosario y la región, visita, disfruta y utiliza las instalaciones, ya no como el Club Español destinado a los inmigrantes españoles, sino que involucra a todos sus habitantes, descendientes de cualquier corriente inmigratoria para conformar y dar sustento en el tiempo a una identidad: la rosarina de hoy." ${ }^{42}$

${ }^{42}$ (De Gregorio, Roberto; Mesanich, Viviana y Sánchez, Ana María. 2012. "Los valores del Complejo Cultural Parque de España". En: Roberto De Gregorio, Viviana Mesanich y Ana María Sánchez (coord. ed.) Complejo Cultural Parque de España, Rosario, s/e, pp. 118-120). 


\section{Bibliografía}

Águila, Verónica; Galassi, Gisela y García, Analía. 2004. “Aquellos años de gala y patriotismo...huellas del asociacionismo español en Rosario". En: Sandra Fernández y María Rosa Oliver (coord.) Catálogo fotográfico del Club Español de Rosario. 1882-1940. Rosario, Club Español de Rosario y Prohistoria, pp. 1522.

Brarda, Analía. 2012 "Entrevista al Arquitecto Fernando Boix”. En: Roberto De Gregorio, Viviana Mesanich y Ana María Sánchez (coord.). Complejo Cultural Parque de España, Rosario, s/e, pp. 92-97.

De Grandis, Nélida. 2007. Los españoles en sociedad: inmigración, territorio y trama asociativa en Rosario. Rosario, el autor.

De Gregorio, Roberto. 2012. “Aportes tentativos para enfocar algunas interpretaciones”. En: De Gregorio, Roberto; Mesanich, Susana y Sánchez, Ana María (coord.). Complejo Cultural Parque de España, Rosario, s/e, pp. 102-117.

De Gregorio, Roberto; Mesanich, Viviana y Sánchez, Ana María. 2012. "Los valores del Complejo Cultural Parque de España”. En: Roberto De Gregorio, Viviana Mesanich y Ana María Sánchez (coord.) Complejo Cultural Parque de España, Rosario, s/e, pp. 118-121.

De Marco, Miguel Ángel. 2012. "La fuerza de un sueño”. En: De Gregorio, Roberto; Mesanich, Susana y Sánchez, Ana María (coord.). Complejo Cultural Parque de España, Rosario, s/e, pp. 14-33.

Fernández, Sandra y Galassi, Gisela. 2006. "En unión y fraternidad”. En: Darío G. Barriera (dir.) y Sandra R. Fernández (comp. del tomo). Nueva Historia de Santa Fe. Tomo VII. Sociabilidad, corporaciones, instituciones (1860-1930), Rosario, Prohistoria Ediciones, pp. 45-65.

Floriani, Héctor. 2012. "La obra del Centro Cultural Parque de España”. En: Roberto De Gregorio, Viviana Mesanich y Ana María Sánchez (coord.) Complejo Cultural Parque de España, Rosario, s/e, pp. 98-101.

Habichayn, Hilda. 1991. "La colectividad española”. En: AA.VV. Rosario. Historias de aquí a la vuelta. Tomo II. Rosario, Ediciones de Aquí a la Vuelta, pp. 1-23.

Iturrieta, Aníbal. 1993. "De la transición democrática al Quinto Centenario (19751991)". En: Pedro Pérez Herrero y Nuria Tabanera (coord.) España / América Latina: un siglo de políticas culturales. Madrid, AIETI/Síntesis-OEI, pp. 181207.

Mateos, Alicia. 2003. "Las políticas urbanísticas para la ciudad de Rosario entre 1976 y 1992”. En I Jornadas de Estudios sobre Rosario y su Región. Viejos problemas, nuevas perspectivas. Universidad Nacional de Rosario, Octubre 8-10, 2003; Rosario, Argentina.

Quiroga, Horacio. 2012. "Guión para hilvanar recuerdos del proyectista ejecutivo". En Roberto De Gregorio, Viviana Mesanich y Ana María Sánchez (coord.) Complejo Cultural Parque de España, Rosario, s/e, pp. 54-83. 
Schmidt, Graciela. 2012. "Participación del Centro de Arquitectos". En: De Gregorio, Roberto; Mesanich, Susana y Sánchez, Ana María (coord.). Complejo Cultural Parque de España, Rosario, s/e, pp. 88-91.

Sonzogni, Élida. 2006. "Un mundo en cambio". En: Darío G. Barriera (dir.) y Marta S. Bonaudo (comp. del tomo) Nueva Historia de Santa Fe. Tomo VI. La organización productiva y política del territorio provincial (1853-1912), Rosario, Prohistoria Ediciones, pp. 9-30.

Videla, Oscar. 2004. "Los españoles en Rosario". En Sandra Fernández y María Rosa Oliver (coord.) Catálogo fotográfico del Club Español de Rosario. 1882-1940. Rosario, Club Español de Rosario y Prohistoria, pp. 11-14. 